\title{
Findings from a Multi-year Study of CT in K-2 Students in Formal and Informal Settings
}

\author{
Tony Lowe \\ School of Engineering Education \\ Purdue University \\ West Lafayette, IN USA \\ lowe46@purdue.edu
}

\author{
Sean Brophy \\ School of Engineering Education \\ Purdue University \\ West Lafayette, IN USA \\ sbrophy@purdue.edu
}

\author{
Monica Cardella \\ School of Engineering Education \\ Purdue University \\ West Lafayette, IN USA \\ mcardell@purdue.edu
}

\begin{abstract}
For the past four years, our research group has conducted a series of NSF funded studies on Computational Thinking (CT) involving elementary school students, parents, and teachers. We developed curriculum, trained teachers, observed classrooms, created museum exhibits, followed students and families, explored theory, and utilized the diverse skills of a large multi-disciplinary research group to understand the intersection of STEM, literacy, and CT. As we close out this grant, we are looking to disseminate our findings, share lessons learned about research methods and data collection, and build collaborations for future research.
\end{abstract}

\section{CCS CONCEPTS}

- Social and professional topics $\rightarrow$ Computational thinking

- Social and professional topics $\rightarrow$ Computer science education

\section{KEYWORDS}

Computational Thinking, P-12, Formal and Informal Instruction, Professional Development

\section{ACM Reference format:}

Tony Lowe, Sean Brophy, Monica Cardella. 2019. Findings from a Multiyear Study of CT in K-2 Students in Formal and Informal Settings. In Proceedings of Innovation and Technology in Computer Science Education (ITiCSE'119), fuly 14-17, 2019, Aberdeen, Scotland UK. ACM, New York, NY, USA, 1 page. https://doi.org/10.1145/3304221.3325585

\section{Introduction}

The INSPIRE research institute received NSF grant No. DRL 1543175 and ECC 1442416 to investigate the development of CT in very young learners from grades K-2. Early efforts built upon an established engineering design curriculum to enhance elements that introduce $\mathrm{CT}$ and allowed for a better understanding of the capabilities for this very young age group [1]. In-service teachers learned about CT through professional development activities.

Permission to make digital or hard copies of part or all of this work for personal or classroom use is granted without fee provided that copies are not made or distributed for profit or commercial advantage and that copies bear this notice and the full citation on the first page. Copyrights for third-party components of this work must be honored. For all other uses, contact the Owner/Author.

ITiCSE '19, fuly 15-17, 2010, Aberdeen, Scotland UK

(C) 2019 Copyright is held by the owner/author(s)

ACM ISBN 978-1-4503-6301-3/19/07.

https://doi.org/10.1145/3304221.3325585
Researchers followed the learning progress of children in the classroom [2], homeschooling [3], and through informal play activities including a newly designed museum exhibit on CT [4], [5].

\section{Lessons on CT Research}

In addition to the findings of $\mathrm{CT}$ development in children, parents, and teachers we also captured experiences about the process of conducting CT research. The research protocols involved hundreds of hours of observations and video data across scores of classrooms, homes, and informal learning environments. Defining effective processes in which to collect, store, and organize this data became critical [6]. Through the project, we worked on evolving and codifying the moving target that is CT. We analyzed the various ways $\mathrm{CT}$ is defined in the literature and attempted to create working definitions [7] and provide data [8].

\section{Future Research}

This summer brings an end to our grant cycle of research but starts the next phase of our investigations into CT. We hope to share some of these ideas and find partners who are also motivated to understand how CT develops in learners.

\section{REFERENCES}

[1] M. M. Hynes et al., "Inspiring computational thinking in young children's engineering design activities," 2016.

[2] E. M. Haluschak, K. M. Tank, T. J. Moore, and A. C. Johnston, "Actions and Approaches of Teachers Communicating Computational Thinking and Engineering Design to First Grade Students," in ASEE Annual Conference and Exposition, 2019.

[3] H. Ehsan, A. Rehmat, H. Osman, I. H. Yeter, and M. Cardella, "Examining the role of parents in promoting computational thinking in children: A focus on homeschool families," in Proceeding of American Society for Engineering Education (ASEE) Conference \& Exposition, 2019.

[4] H. Ehsan, C. Ohland, T. Dandridge, and M. Cardella, "Computing for the Critters: Exploring Computational Thinking of Children in an Informal Learning Setting," in 2018 IEEE Frontiers in Education Conference (FIE), 2018, pp. $1-5$.

[5] H. Ehsan and M. E. Cardella, "Capturing the Computational Thinking of Families with Young Children in Out-of-School Environments," in 124th ASEE Annual Conference and Exposition, 2017.

[6] I. H. Yeter et al., "Design and implementation of data collection in a large-scale, multi-year pre-college engineering study: A retrospective," in ASEE Annual Conference and Exposition, 2019.

[7] T. Lowe and S. Brophy, "An operationalized model for defining computational thinking," in Frontiers in Education, 2017.

[8] T. Lowe and S. Brophy, "Identifying Computational Thinking in Storytelling Literacy Activities with Scratch Jr.," in ASEE Annual Conference Proceedings, 2019, p. 10. 